\title{
The effect of septal lesions on ethanol consumption by rats
}

\author{
PHILLIP R. GODDING, ERNEST D. KEMBLE, and W. MILES COX \\ University of Minnesota, Morris, Minnesota 56267
}

\begin{abstract}
The effect of septal lesions on consumption of a sucrose solution containing $4.75 \%$ ethanol was assessed using two-bottle and one-bottle tests. Septal and control rats showed very similar levels of alcohol consumption in both tests. During two-bottle testing, both groups demonstrated a clear preference for sucrose solution. During the 15-min one-bottle test, alcohol intake was substantial (means $=2.93$ and $2.95 \mathrm{ml} / \mathrm{kg}$ ) and produced obvious symptoms of inebriation. It is concluded that self-administration of ethanol under these conditions is an appropriate method for brief studies of septal-ethanol interactions.
\end{abstract}

Although the reticular formation has long been recognized as a major site of ethanol action (e.g., Himwich, DiPerri, Dravid, \& Schweigerdt, 1966; Kalant, 1961), a number of recent studies also suggest an important role for the septal area and other limbic structures (Harvey, Heller, Moore, Hunt, \& Roth, 1964; Meyers \& Veale, 1972; St.-Laurent, 1972). Investigations of the interactive behavioral effects of septal lesions and alcohol ingestion would therefore seem to be of interest.

Although several techniques are widely employed to administer ethanol, the potential aversive properties of administration via routes such as intraperitoneal injection or intragastric intubation make self-administration more desirable (Meyers \& Veale, 1972). If relatively low ethanol concentrations (approximately $5 \%$ ) are presented in a palatable sucrose solution and combined with a limited fluid regimen, rats will drink sufficient quantities of ethanol to produce reliable behavioral effects and symptoms of inebriation (Cox, 1981). Since septal lesions are also known to increase reactivity to the taste properties of both palatable and unpalatable solutions (Beatty \& Schwartzbaum, 1967, 1968), however, it might be expected that these lesions would substantially alter the consumption of a flavored alcohol solution. If so, self-administration would not be appropriate for studies of septal-ethanol interactions. The present experiments investigated the effect of septal lesions on consumption of an alcohol-sucrose mixture known to be behaviorally effective in intact rats (Cox, 1981).

\section{METHOD}

The subjects were 19 experimentally naive female albino rats (Holtzman Company, Madison, Wisconsin) weighing 203$238 \mathrm{~g}$ at the time of surgery. The rats were housed and tested in $23 \times 38 \times 23 \mathrm{~cm}$ cages (Wahman, LC-28) adapted to hold two

Requests for reprints should be sent to Ernest Kemble or W. Miles Cox, Division of Social Sciences, University of Minnesota, Morris, Minnesota 56267. Phillip R. Godding is now a graduate student at North Dakota Sta te University. 100-ml graduated drinking cylinders. Unless otherwise specified, the rats had ad-lib access to Purina Lab Chow.

Prior to group assignment, tube position preferences were assessed by providing ad-lib access to two tubes of tap water and measuring daily consumption from each position for 2 days. The animals were then randomly assigned to septal or control groups from pairs of rats having similar position preferences.

Septal lesions $(N=10)$ were then produced stereotaxically by passing $2.0 \mathrm{~mA}$ anodal dc through the uninsulated tip of a stainless steel pin for $20 \mathrm{sec}$. Three (operated-control) rats received identical treatment, except for current passage, and the remaining (incision-control) rats received a scalp incision only. The two control groups did not differ on any measure, and their data were combined for subsequent analyses. Further details of the surgical procedures are available in an earlier publication (Kemble \& Nagel, 1975). Rats were allowed to recover for 2 weeks.

At the beginning of testing, all rats exceeded their preoperative weights (mean $=276 \mathrm{~g}$ ), with no suggestion of group differences throughout testing (Us $>38$, ps $>.10$ ). After recovery, the preoperative tube position preference test with tap water was repeated. Next, the alcohol consumption of the two groups was compared with two-bottle preference tests for 2 days. One drinking tube was filled with a $10 \%$ sucrose solution $(10 \mathrm{~g}$ sucrose $/ 100 \mathrm{ml}$ tap water), and the remaining tube with a $10 \%$ sucrose solution containing $4.75 \%$ ethanol $(5 \mathrm{ml} 95 \%$ ethanol/95 $\mathrm{ml}$ sucrose). The positions of the sucrose and the sucrose-ethanol tubes were reversed on the 2 nd test day. At the conclusion of the two-bottle preference test, the rats were adapted to a limited food and water regimen for 11 days. Each day, the rats were permitted to drink tap water from a single drinking tube (position alternated daily) for $15 \mathrm{~min}$ and then were given $9 \mathrm{~g}$ of Purina Lab Chow. This regimen reduced body weights to $90 \%( \pm 5 \%)$ of ad-lib values by the end of adaptation, but there were no group differences $[U(9,10)=54, p>.10]$. On Day 12, the sucrose-ethanol solution was substituted for tap water in the drinking tube for a 15-min test.

At the conclusion of testing, all experimental rats were transcardially perfused under deep anesthesia, and thioninstained coronal sections through the lesion area were prepared.

\section{RESULTS AND DISCUSSION}

The septal lesions invariably included extensive damage to the precommissural portions of the medial and lateral septal nuclei. Damage to surrounding structures was slight and did not contribute to the experi- 


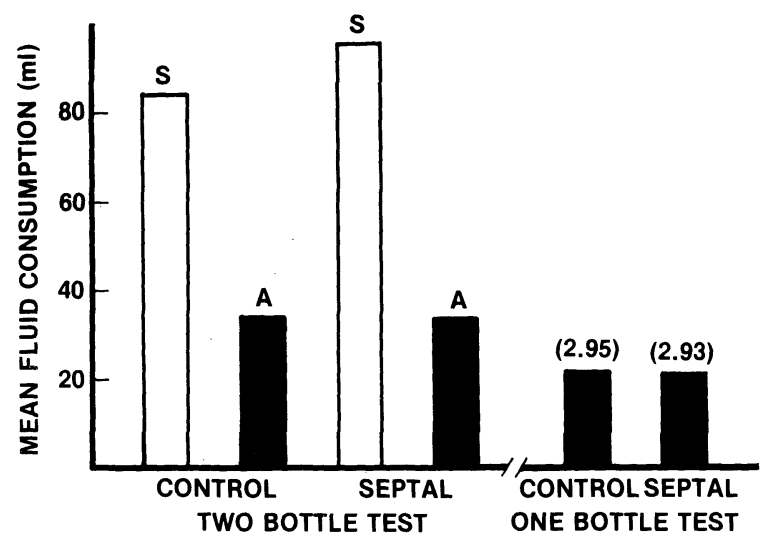

Figure 1. Mean consumption of sucrose solution (S) and sucrose-alcohol solution (A) for control and septal groups during two-bottle testing and sucrose-alcohol consumption during onebottle testing. Numbers in parentheses express consumption as milliliters of alcohol per kilogram of body weight.

mental results in any obvious way. All septal rats showed transient "septal rage," but these symptoms disappeared well before experimental testing. There was no suggestion of a shift in tube position preference postoperatively in either group. When both tubes were filled with tap water, the control and septal animals drank an average of $54 \%$ and $56 \%$ of their respective total fluid intakes from the preferred fluid position.

The results of the two consummatory tests are summarized in Figure 1. The 2 days of testing with the twobottle technique have been averaged for this figure. It can be seen that both groups showed a strong preference for sucrose over alcohol solution (sign test, $p<.05$, for both groups). The consumption of sucrose solution by the control and septal groups was quite similar on the 1st test day (means $=59.1 \mathrm{ml}$ and $61.1 \mathrm{ml}$, respectively). On the 2nd day the septal group drank substantially more sucrose than the control group (means $=83.9 \mathrm{ml}$ and $67.1 \mathrm{ml}$, respectively), but this difference was only marginally significant $[t(17)=1.95, .05<\mathrm{p}<.10]$. The alcohol consumption of both groups was very similar on both test days, with no suggestion of group differences $(F<1.0)$. Control and septal groups, however, did show a marginally reliable decline in alcohol consumption from the 1 st (means $=26.3 \mathrm{ml}$ and $28.0 \mathrm{ml}$, respectively) to the 2nd (means $=22.0 \mathrm{ml}$ and $22.4 \mathrm{ml}$, respectively) test day $[\mathrm{F}(1,17)=3.37, .05<\mathrm{p}<.10]$.

Alcohol consumption by the control and septal groups during the one-bottle test expressed either as milliliters consumed (means $=15.7$ and 15.8 , respectively) or as milliliters of alcohol per kilogram of body weight (means $=2.95$ and 2.93, respectively) was quite similar, with no suggestion of group differences (ts $<1.0$ ). Individual doses ranged from 1.66 to $3.69 \mathrm{ml} / \mathrm{kg}$, but only three rats consumed less than $2.65 \mathrm{ml} / \mathrm{kg}$. In virtually all cases, impairments in gait, posture, and equilibrium were obvious.
The results of this experiment demonstrate that septal lesions do not alter consumption of a sucrose solution containing $4.75 \%$ ethanol and that, under onebottle 15 -min access conditions, the fluid is consumed in sufficient quantities to produce reliable behavioral effects (Cox, 1981; Eckardt, Skurdal, \& Brown, 1974; Ley \& Crow, 1979). At the conclusion of this experiment, all rats received 2 additional days of one-bottle access to the ethanol-sucrose solution in conjunction with further behavioral testing. Again, there was no suggestion of lesion-induced alteration in consumption.

It is possible, of course, that septal lesion effects on consumption might appear with alterations in ethanol concentration, solution palatability, or long-term continuous exposure to an alcohol-sucrose mixture. In fact, the trend toward the septal animals' increased consumption of the sucrose solution during two-bottle testing in the present experiment suggests that the lesions might eventually have induced characteristic taste hyperreactivity (Beatty \& Schwartzbaum, 1967, 1968). Nevertheless, it seems clear that self-administration can be effectively utilized for investigations of septalethanol interactions that do not require prolonged consumption.

\section{REFERENCES}

Beatty, W. W., \& Schwartzbaum, J. S. Enhanced reactivity to quinine and saccharin solutions following septal lesions in the rat. Psychonomic Science, 1967, 8, 483-484.

Beatty, W. W., \& Schwartzbaum, J. S. Consummatory behavior for sucrose following septal lesions in the rat. Journal of Comparative and Physiological Psychology, 1968, 65, 93-102.

Cox, W. M. Simultaneous incentive contrast effects with alcoholic and nonalcoholic beverages as the discriminanda for reward magnitude. Physiological Psychology, 1981, 9, 276-280.

Eckardt, M. J., Skurdal, A. J., \& Brown, J. S. Conditioned taste aversion produced by low doses of alcohol. Physiological Psychology, 1974, 2, 89-92.

Harvey, J. A., Heller, A., Moore, R. Y., Hunt, H. F., \& Roth, L. J. Effect of central nervous system lesions on barbiturate sleeping time in the rat. Journal of Pharmacology and Experimental Therapeutics, 1964, 144, 24-36.

Himwich, H. E., DiPerri, R., Dravid, A., \& Schweigerdt, A. Comparative susceptibility to alcohol of the cortical area and midbrain reticular formation of the cat. Psychosomatic Medicine, 1966, 28, 458-463.

KALANT, H. The pharmacology of alcohol intoxication. Quarterly Journal of Studies on Alcohol, 1961, 22, 1-23.

Kemble, E. D., \& Nagel, J. A. Persistent depression of rearing behavior in rats after extensive septal lesions. Journal of Comparative and Physiological Psychology, 1975, 89, 747-758.

LEY, M. F., \& CRow, L. T. The effects of alcohol on learned helplessness. Physiological Psychology, 1979, 7, 387-390.

Meyers, R. D., \& Veale, W. L. The determinants of alcohol preference in animals. In B. Kissin \& H. Begleiter (Eds.), The biology of alcoholism (Vol. 2): Physiology and behavior. New York: Plenum, 1972.

St.-Laurent, J. Brain centers of reinforcement and the effects of alcohol. In B. Kissin \& H. Begleiter (Eds.), The biology of alcoholism (Vol. 2): Physiology and behavior. New York: Plenum, 1972.

(Received for publication February 6, 1982.) 